\title{
PARCERIA NA PREVENÇÃO E COMBATE AO ASSÉDIO MORAL: RELATO DE EXPERIÊNCIA UFGD-UFSCAR
}

\author{
Ariane Rigotti ${ }^{1}$ \\ Silvana Ap. Perseguino²
}

\begin{abstract}
Resumo
Este artigo reflete, através de um relato de experiência, sobre como as parcerias institucionais podem ser benéficas no âmbito das Ouvidorias universitárias. No contexto de evento formatado pela Ouvidoria da Universidade Federal da Grande Dourados no ano de 2017, com o intuito de fomentar o debate visando ao combate às violências no ambiente universitário, dentre elas o assédio moral, estabeleceu-se uma parceria com o Ministério Público do Trabalho de Dourados e com a Ouvidoria da Universidade Federal de São Carlos. Através da troca de experiência, utilizando a metodologia da roda de conversa, foi possível demonstrar à comunidade que as violências não são exclusividade de uma única instituição e que trazer à tona o debate é o começo da prevenção. Respeitando as identidades próprias de cada universidade, também foram identificadas similaridades institucionais e as possibilidades de protagonismo das Ouvidorias no processo de combate ao assédio moral no ambiente de trabalho.
\end{abstract}

Palavras-chave: Ouvidoria. Assédio Moral. Universidades Federais.

\section{DOI:10.37814/2594-5068.2019v2.p107-118}

1 Ouvidora-Geral da Universidade Federal da Grande Dourados (UFGD) desde 2015, com formação em Direito pela Universidade Estadual do Mato Grosso do Sul e MBA em Gestão de Pessoas pela Anhanguera Educacional. (rigotti81@gmail.com)

2 Ouvidora-Geral da Universidade Federal de São Carlos (UFSCar) no período de 2014 a 2017; Doutora e Mestre em Ciência, Tecnologia e Sociedade pela Universidade Federal de São Carlos; Especialista em Gestão Organizacional e Recursos Humanos pela Universidade Federal de São Carlos; e Licenciada em Letras (Português-Francês) pela Universidade Estadual “Júlio de Mesquita Filho” (UNESP). (silvana.perseguino@gmail.com) 


\begin{abstract}
This paper reflects, through an experience report, on how institutional partnerships can be beneficial in the scope of university Ombudsmen. In the context of an event formatted by the Ombudsman's Office of the Federal University of São Carlos in the year 2017, in order to foment the debate aimed at fighting violence in the university environment, among them harassment, a partnership was established with the Public Ministry of Work of Dourados and with the Ombudsman's Office of the Federal University of São Carlos. Through the exchange of experience, using the methodology of the conversation wheel, it was possible to demonstrate to the community that violence is not exclusive to a single institution and that bringing up the debate is the beginning of prevention. Respecting the identities of each university, institutional similarities and the possibilities of the Ombudsman's role in the process of combating harassment in the workplace were also identified.
\end{abstract}

Keywords: Ombudsman. Harassment. Federal Universities. 


\section{INTRODUÇÃO}

A partir da segunda metade dos anos 1980, em um contexto de redemocratização do País, o Brasil restabeleceu o Estado Democrático de Direito, configurando-se como uma estrutura de democracia participativa. A Constituição cidadã de 1988 possibilitou a "abertura do Estado à efetiva participação do povo em sua gestão e controle" (BRASIL, 2012), estabelecendo em seu art. 37 que:

AAdministração Pública direta e indireta de qualquer dos Poderes da União, dos Estados, do Distrito Federal e dos Municípios obedecerá aos princípios de legalidade, impessoalidade, moralidade, publicidade e eficiência. (BRASIL, 1988)

Instituída pelo Decreto n ${ }^{\circ} 8.243 / 2014$, a Política Nacional de Participação Social, em seu art. $2^{\circ}$, inciso $\mathrm{V}$, define a Ouvidoria Pública federal como:

instância de controle e participação social responsável pelo tratamento das reclamações, solicitações, denúncias, sugestões e elogios relativos às políticas e aos serviços públicos, prestados sob qualquer forma ou regime, com vistas ao aprimoramento da gestão pública. (BRASIL, 2014)

As Ouvidorias se projetam, dessa forma, como instâncias de interlocução e mediação, promovendo o diálogo com a sociedade e defendendo os direitos do cidadão em suas relações com as organizações do Poder Executivo Federal. Para ROMÃO (2013, p. 2), "esse é o grande papel que cabe às Ouvidorias realizar: promover a efetividade dos direitos humanos no Brasil".

Vale destacar o esforço da Ouvidoria-Geral da União ao longo dos últimos dez anos no sentido de congregar as Ouvidorias em uma rede hoje praticamente consolidada, sobretudo através da adesão ao Sistema e-Ouv, contribuindo, e muito, para a profissionalização das Ouvidorias Públicas e possibilitando trocas e aprendizados compartilhados.

Com a Lei n 13.460 (BRASIL, 2017), que estabelece o Código de Defesa dos Usuários de Serviços Públicos, as Ouvidorias passaram a ter as seguintes atribuições:

Art. 13. As Ouvidorias terão como atribuições precípuas, sem prejuízo de outras estabelecidas em regulamento específico:

I - promover a participação do usuário na Administração Pública, em cooperação com outras entidades de defesa do usuário;

II - acompanhar a prestação dos serviços, visando a garantir a sua efetividade;

III - propor aperfeiçoamentos na prestação dos serviços;

IV - auxiliar na prevenção e correção dos atos e procedimentos incompatíveis com os princípios estabelecidos nesta Lei;

V - propor a adoção de medidas para a defesa dos direitos do usuário, em observância às determinações desta Lei;

$\mathrm{VI}$ - receber, analisar e encaminhar às autoridades competentes as manifestações, acompanhando o tratamento e a efetiva conclusão das manifestações de usuário perante órgão ou entidade a que se vincula; $\mathrm{e}$

VII - promover a adoção de mediação e conciliação entre o usuário e o órgão ou a entidade pública, sem prejuízo de outros órgãos competentes. 
Portanto, as Ouvidorias reforçam seu importante papel de acompanhamento da gestão pública e de promotoras da participação cidadã, bem como consolidam suas atividades já desenvolvidas de mediação e conciliação entre o cidadão e o órgão ao qual estão vinculadas.

Com pouco mais de vinte anos de existência, é nesse contexto que as Ouvidorias Públicas universitárias vêm cada vez mais contribuindo para os processos de melhoria institucional, configurando-se como significativos instrumentos de gestão (PERSEGUINO, 2017).

Em um cenário de expressiva expansão e transformações profundas desencadeadas pelos processos de ações afirmativas e democratização de acesso, mas com severas restrições orçamentárias (ANDIFES, 2016; VIEIRA, 2015; 2016) e de pessoal, as Instituições Federais de Ensino Superior (IFES) tornaram-se mais inclusivas e abrangentes, porém com um ambiente muito mais complexo e repleto de tensões e conflitos. Nesse universo de relações diversas, não raro extremamente esgarçadas, adquire importância o protagonismo das Ouvidorias como instâncias pedagógicas para a prevenção e o combate às violências presentes no cotidiano das IFES.

A título de contribuição, este artigo reflete, através de um relato de experiência no âmbito de evento proposto e realizado pela Ouvidoria da Universidade Federal da Grande Dourados no ano de 2017, sobre como as parcerias institucionais podem ser benéficas para as Ouvidorias universitárias, em especial no que tange à prevenção e ao combate ao assédio moral no ambiente de trabalho.

Sem a pretensão de esgotar o tema, mas para melhor ilustrar esse fenômeno e a relevância do relato aqui expresso, faremos um esforço de conceituação, à luz do que tem sido sistematizado na literatura. O assédio moral tem sido objeto de análise por parte de juristas e pesquisadores em diferentes áreas e espera-se que o referencial teórico apresentado a seguir possa contribuir para a reflexão no âmbito da atuação das Ouvidorias em geral.

\section{O ASSÉDIO MORAL NAS ORGANIZAÇÕES}

Desde muito tempo, no mundo globalizado, não é novidade que a tônica dos ambientes corporativos tem sido a competição e a rivalidade, muitas vezes incentivadas pelos próprios gestores na busca por melhores desempenhos, em detrimento da cooperação e solidariedade. Nesse contexto, o assédio moral vem se destacando como um fenômeno mundial com contornos de violência difusa, muitas vezes invisível, acarretando resultados nefastos para o indivíduo e para a organização. Assim, entender o que é e como se manifesta configura o primeiro passo para a prevenção.

Segundo HELOANI (2003), as pesquisas sobre assédio moral têm raízes históricas na Suécia, através dos trabalhos desenvolvidos a partir de 1996 pelo psicólogo do trabalho Heinz Leyman, a respeito do que denominou "psicoterror". Porém, foi com o sucesso do livro Assédio moral, publicado dois anos depois pela psiquiatra e psicanalista francesa Marie-France Hirigoyen, que o termo se popularizou e impulsionou os debates no âmbito do trabalho e na esfera familiar. Uma das grandes contribuições de Hirigoyen foi discordar de algumas teorias psicanalíticas que atribuíam a culpa ao agredido, trazendo à tona uma abordagem mais humana da temática.

110 | Revista Científica da Associação Brasileira de Ouvidores/Ombudsman - Ano 2 - nº 2 - 2019 
A principal característica do assédio moral é a intencionalidade, a imposição a situações de pressão, humilhantes e vexatórias, por parte de indivíduos ou grupos. Não se pode deixar de considerar que o assédio moral, de forma tangencial, tem relação com questões de poder, gênero, raça e até de cunho religioso. Ocorre de forma constante e progressiva, em um processo destrutivo que busca minar a vontade do outro, acarretando sofrimento e patologias graves. Para HIRIGOYEN (2001), o assédio moral se reflete em condutas abusivas expressas em comportamentos, palavras, atos e gestos que podem ocasionar danos à personalidade, à dignidade ou à integridade física ou psíquica de uma pessoa. Um processo que degrada e destrói as relações e o ambiente de trabalho.

Quem sofre o assédio, na maioria dos casos, teme formalizar a denúncia, com receio de perseguições, demissão ou exposição pública, potencializando o sofrimento. Isso quando há a possibilidade ou canal de formalização. Ao contrário do que possa parecer, as vítimas nem sempre são indivíduos frágeis ou fracos. Na visão de HELOANI (2003, p. 59):

Embora seus agressores tentem desqualificá-las, as vítimas não costumam ser indivíduos doentes ou frágeis. São pessoas que tomam, de forma consciente ou inconsciente, posições de enfrentamento, algumas vezes questionando privilégios ou situações injustas. Com isso, tornam-se os alvos das agressões. Isso ocorre justamente por não se deixarem dominar, por não se curvarem.

O Conselho Nacional de Justiça, em seu portal, esclarece que não há legislação ou lei específica para "repressão e punição daqueles que praticam o assédio moral. No entanto, na Justiça do Trabalho, a conduta de assédio moral, se caracterizada, gera indenização por danos morais e físicos" (CNJ, 2016, p. 1), podendo ser enquadrada no âmbito da Consolidação das Leis Trabalhistas (CLT) e da Justiça Criminal. Em função da dificuldade de caracterização, faz recomendações para quem sofre o abuso, como: anotar os fatos relevantes, evitar encontros com o agressor sem testemunhas, buscar apoio dos colegas que testemunharam, da família e dos amigos.

De acordo com HELOANI (2003, p. 61):

apesar dessas dificuldades, esforços vêm sendo realizados em diversos países, inclusive no Brasil, para tornar a prática do assédio moral passível de pena. Mais do que a lei, no entanto, é preciso criar a consciência geral de transparência, contribuindo para que o ambiente de trabalho seja saudável e adequado ao desenvolvimento das potencialidades dos indivíduos.

Na esfera pública brasileira, a Secretaria de Administração de Santa Catarina elaborou um manual de diretrizes e procedimentos, possibilitando caracterizar o assédio moral, classificando-o em três categorias:

- Vertical Descendente: tipo mais comum, no qual a pessoa que detém o poder prejudica o(s) subordinado(s).

- Horizontal: o(s) agressor(es) apresenta(m) o mesmo nível hierárquico da vítima.

- Vertical Ascendente: acontece quando um subordinado ou vários assediam uma pessoa que pertence a um nível hierárquico superior. (SANTA CATARINA, 2010, p. 17) 
Embora possa haver eventualmente sobreposição, faz-se necessário distinguir entre o que é ou não assédio moral no ambiente de trabalho, na busca de evitar a confusão com conflitos pontuais. Resumidamente, o quadro a seguir ilustra alguns exemplos:

\section{QUADRO 1 - Distinção do Assédio Moral de Figuras Afins}

\begin{tabular}{|l|l|}
\hline \multirow{5}{*}{ Características do assédio moral } & Deterioração proposital das condições de trabalho. \\
\cline { 2 - 2 } & Isolamento e recusa de comunicação. \\
\cline { 2 - 3 } & Atentado contra a dignidade. \\
\cline { 2 - 2 } & Violência verbal, física ou sexual. \\
\hline \multirow{4}{*}{$\begin{array}{l}\text { Situações que não se } \\
\text { caracterizam necessariamente } \\
\text { como assédio moral }\end{array}$} & Estresse causado pela execução de alguma atividade. \\
\hline & $\begin{array}{l}\text { Competitividade no trabalho e conflitos pontuais entre cole- } \\
\text { gas de trabalho. }\end{array}$ \\
\hline & Chefias exigentes ou perfeccionistas. \\
\hline & $\begin{array}{l}\text { Imposições profissionais em consonância com o contrato de } \\
\text { trabalho. }\end{array}$ \\
\hline & $\begin{array}{l}\text { Más condições de trabalho e sobrecarga de trabalho sem } \\
\text { exagero ou intenção de prejudicar o trabalhador e não dire- } \\
\text { cionadas a uma única pessoa ou grupo específico. }\end{array}$ \\
\hline
\end{tabular}

Fonte: SANTA CATARINA (2010), com adaptações

O ambiente universitário, um espaço efervescente de produção e disseminação de conhecimento, não está imune a esse processo. A competição e as disputas pelo poder se fazem presentes nesse universo comumente politizado e, não raro, também polarizado. Nesse contexto, o assédio moral pode ocorrer tanto no âmbito administrativo quanto acadêmico, envolvendo todas as categorias presentes na organização: docentes, alunos, técnico-administrativos e, em especial, uma categoria cada vez mais presente no contexto das IFES, para muitos invisível e sem poder de ação, que são os terceirizados, representados pelos prestadores de serviços diversos e estagiários.

Especificamente no universo das IFES, identificaram-se alguns estudos que retratam a ocorrência do assédio moral, suas características e consequências. MUNIZ, MACHADO e VIEIRA (2011), em estudo de caso realizado no âmbito do curso de Administração de uma IFES no estado de Pernambuco, abordam o assédio moral na relação professor-aluno, a partir da perspectiva dos alunos. 
Os resultados indicam que $40,3 \%$ dos participantes da pesquisa afirmaram já ter sofrido assédio moral em sala de aula.

A partir da escuta de 152 professores de um dos campus da Universidade Federal do Piauí, ARAÚJO e NASCIMENTO (2014) sistematizaram dados que, de alguma forma, retratam atos negativos que podem se configurar como assédio entre docentes. Na visão dos autores, os resultados preocupam pelas situações que deflagram o assédio se repetirem sem nenhuma solução institucional.

GUIMARÃES, CAÇADO e LIMA (2015, p. 151), também utilizando o estudo de caso, com análise de processo administrativo institucional, evidenciam um caso de assédio moral do tipo vertical descendente em uma IFES, caracterizado pelo abuso de poder, autoritarismo e manipulação, ocasionando consequências sérias à saúde física e emocional do assediado. Na visão dos autores, a "não atuação da área de Recursos Humanos na intermediação do conflito, a cultura e a estrutura da instituição podem ter favorecido a ocorrência do caso e motivado a impunidade do assediador".

Visando contribuir para as ações de intervenção no combate ao assédio moral e organizacional, aplicáveis em qualquer realidade, SOBOLL (2017) apresenta alguns princípios que podem orientar estratégias institucionais de ação, resumidos no quadro a seguir:

\section{QUADRO 2 - Subsídios para Políticas ou Intervenções mo Combate ao Assédio}

\begin{tabular}{|l|l|}
\hline \multirow{5}{*}{$\begin{array}{l}\text { Princípios norteadores } \\
\text { de possíveis ações }\end{array}$} & $\begin{array}{l}\text { 1. Reconhecer o assédio moral como um problema real no coti- } \\
\text { diano do trabalho contemporâneo, passível de ocorrer em qual- } \\
\text { quer realidade. }\end{array}$ \\
\cline { 2 - 3 } & 2. Fazer a melhor intervenção no espaço de ação que se tem. \\
\cline { 2 - 3 } & 3. Considerar as condições de realidade. \\
\cline { 2 - 3 } & $\begin{array}{l}\text { 4. Priorizar a promoção da dignidade no trabalho e, se possível, } \\
\text { a transformação da forma de organização do trabalho. }\end{array}$ \\
\hline
\end{tabular}

Fonte: SOBOLL (2017), com adaptações

Com base nesses princípios, a autora reconhece a Ouvidoria como "uma instância com autonomia em relação às demais áreas de gestão" e que pode ser um recurso com possibilidades de "apoio à superação das dificuldades nas relações no trabalho" (SOBOLL, 2017, p. 41).

Dentro do espaço de ação possível, foi nessa perspectiva que o evento da UFGD foi formatado e possibilitou-se a parceria com o Ministério Público do Trabalho de Dourados e com a Ouvidoria da UFSCar. 


\section{O EVENTO \#UFGD SEM OPRESSÃO: MOMENTO DE REFLEXÃO E INTERVENÇÃO}

A Universidade Federal da Grande Dourados (UFGD), anteriormente campus da Universidade Federal do Mato Grosso do Sul (UFMS), foi criada no ano de 2005 por meio da Lei $n^{\circ} 11.153$, de 29 de julho de 2005 (BRASIL, 2005). Uma universidade relativamente jovem, ela conta atualmente com 7.461 alunos na graduação presencial e 623 alunos nos cursos de graduação na modalidade de Educação a Distância (EaD). Conta, ainda, com 1.068 alunos matriculados nos programas de pós-graduação stricto sensu. Sua estrutura é composta de sete pró-reitorias, doze faculdades e um hospital universitário onde atuam cerca de 924 técnico-administrativos, 585 docentes e 240 trabalhadores terceirizados.

O Plano de Desenvolvimento Institucional 2013-2017 - PDI (UFGD, 2013, p. 16) prevê como missão e visão de futuro, respectivamente:

Gerar, construir, sistematizar, inovar e socializar conhecimentos, saberes e valores, por meio do ensino, pesquisa e extensão de excelência, formando profissionais e cidadãos capazes de transformar a sociedade no sentido de promover desenvolvimento sustentável com democracia e justiça social.

[...]

Ser uma instituição reconhecida nacional e internacionalmente pela excelência na produção do conhecimento e por sua filosofia humanista e democrática.

A Ouvidoria da UFGD existe praticamente desde o ano de criação da Universidade por meio da previsão na estrutura organizacional. A partir de 2015, passou por um processo de reestruturação, sistematizando os fluxos internos e externos, elaborando seu Regimento Interno e adotando o sistema e-Ouv, desenvolvido pela Controladoria-Geral da União, possibilitando sua atuação em rede.

Seguindo os preceitos de uma Ouvidoria Pública, isto é, a promoção do aprimoramento constante de políticas e de serviços públicos, tendo em vista o fortalecimento da participação social como meta e como método de realização do Estado Democrático de Direito, a Ouvidoria da UFGD sempre primou pelo atendimento de excelência às manifestações dos cidadãos.

Assim, com base em manifestações de 2015 e 2016, a Ouvidoria elaborou um projeto de extensão denominado "\#UFGD Sem Opressão", submetido e aprovado em edital de 2016, e executado no ano de 2017. O projeto contou com o apoio da Reitoria e teve como objetivos: (i) incentivar a melhoria das relações nos ambientes de trabalho; e (ii) contribuir para a melhoria institucional através da disseminação de conhecimento relacionado às violências em geral, propondo a troca de ideias e a busca de soluções compartilhadas.

Inspirado na obra de HIRIGOYEN (2006) e do Ministério Público Federal (BRASIL, 2016), o projeto buscou proporcionar à comunidade espaços de apresentação, discussão e geração de conhecimento a respeito de temáticas que pudessem integrar uma formação social mais ampla, voltada para o exercício da cidadania.

Em formato de rodas de conversa, o projeto também se pautou pelos princípios das metodologias ativas, que valorizam o diálogo, a problematização da realidade vivenciada e a ampla

114 | Revista Cientifica da Associação Brasileira de Ouvidores/Ombudsman - Ano 2 - n 2 - 2019 
participação dos envolvidos no debate e na construção de soluções para os problemas. Na visão de BORGES e ALENCAR (2014, p. 129), as metodologias ativas podem ser definidas como:

formas de desenvolver o processo de aprender, utilizando experiências reais ou simuladas, visando às condições de solucionar, com sucesso, desafios advindos das atividades essenciais da prática social, em diferentes contextos.

Nesse formato, ao longo do ano de 2017, foram realizados três eventos sobre as seguintes temáticas: violência contra mulheres no ambiente de trabalho, assédio moral no ambiente de trabalho e LGBTfobia, conforme material de divulgação da Figura 1.

\section{FIGURA 1 - Artes dos Eventos do Projeto \#UFGD Sem Opressão}
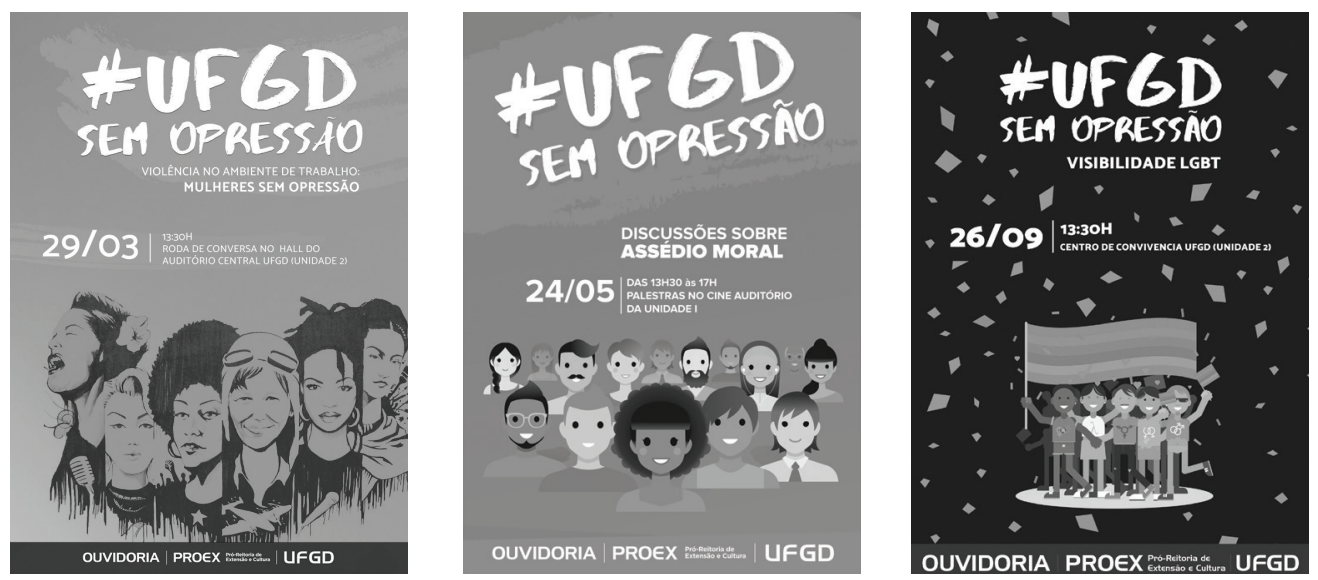

Fonte: OUVIDORIA UFGD (2017)

Os eventos contaram com a participação de especialistas nos temas, servidores técnico-administrativos e docentes, bem como pessoas da comunidade externa, transformando os encontros em momentos enriquecedores e de grande troca de experiências. Pelo escopo deste trabalho, trataremos apenas do segundo evento, cuja temática foi o assédio moral.

Realizado em maio de 2017, mês em que se comemora o dia do trabalhador, o evento Discussões Sobre Assédio Moral propiciou um momento de abordagem e reflexão sobre conceitos legais, acadêmicos e organizacionais, visando caracterizar o assédio moral no ambiente de trabalho. Participaram como palestrantes a Procuradora do Ministério Público do Trabalho na cidade de Dourados e região, compartilhando a experiência em contendas do MPT na temática do assédio moral, e a Ouvidora à época da Universidade Federal de São Carlos (UFSCar), coautora deste trabalho, compartilhando a vivência em uma Ouvidoria universitária relacionada ao tema assédio moral. 
No âmbito jurídico, objeto da palestra da Procuradora do MPT, foi possível conhecer os atos normativos (leis e projetos de leis) que, de alguma forma, podem ou poderão dar proteção legal em casos constatados de assédio moral nas organizações, apesar de ainda não haver ordenamento jurídico específico no contexto brasileiro. Outros tópicos tratados na palestra foram: conceituação do que é ou não assédio; problemas de saúde mais comuns decorrentes do assédio - que vão desde a diminuição da concentração e da capacidade de memorização até casos graves de depressão e uso de álcool e drogas; medidas preventivas e repressivas relacionadas ao assédio; e exemplos de casos concretos julgados na esfera jurídica, acarretando indenizações por danos morais. Alguns destaques da palestra referentes à prevenção: necessidade de um gerenciamento proativo; criação de espaços de confiança; códigos de ética; processos educativos; instituição de políticas de qualidade de vida no trabalho.

No contexto universitário, objeto da palestra da Ouvidora da UFSCar, foi possível ilustrar os indicadores institucionais da Universidade, demonstrando seu crescimento e a diversificação de sua comunidade; descrever a atuação da Ouvidoria em parceria com as diversas unidades da Instituição no combate às violências, em especial com a Secretaria de Ações Afirmativas, Diversidade e Equidade; enfatizar a conceituação do que é ou não assédio no ambiente de trabalho e no contexto universitário; bem como destacar possíveis ações institucionais de prevenção e combate ao assédio. São elas: fortalecimento das comissões de ética; aprimoramento dos canais de denúncia e mecanismos de apuração como um posicionamento institucional; criação de grupos multidisciplinares para análise das denúncias, propiciando uma visão ampliada e sistêmica do problema; suporte às vítimas através do acolhimento e escuta de qualidade; ações contínuas e permanentes de esclarecimento e tipificação das violências, inclusive através de programas de capacitação; esforço institucional de criação de ambientes de trabalho acolhedores e cooperativos.

Especificamente em relação ao contexto das universidades federais, também evidenciou-se que 0 assédio moral atinge a todas as categorias presentes na comunidade, especialmente aquelas mais fragilizadas na estrutura organizacional como os prestadores de serviços terceirizados, bem como os estagiários.

Avaliado positivamente pelos participantes, que puderam entender o que significa o assédio moral, além de relatar e compartilhar suas experiências, o evento demonstrou o protagonismo da Ouvidoria da UFGD no processo de construção de conhecimento sobre o tema, através do diálogo com a comunidade, com a contribuição de parceiros externos.

Isso confirma o que preconiza CYRILLO (2016, p. 208) a respeito do papel das Ouvidorias na atualidade:

A face pedagógica do trabalho realizado nas Ouvidorias envolve o papel proativo do Ouvidor enquanto disseminador de conceitos positivos quanto à importância da participação do cidadão nos processos de gestão pública, conclamando-o e estimulando-o a utilizar-se dos canais colocados à sua disposição.

No que tange às parcerias institucionais com o MPT e a Ouvidoria da UFSCar, o evento possibilitou à comunidade esclarecer dúvidas no âmbito jurídico, bem como conhecer as similaridades entre as duas instituições universitárias, a partir da constatação de que as violências rela- 
cionadas ao assédio moral não são exclusividade de uma única instituição e têm características muito parecidas.

\section{CONSIDERAÇÕES FINAIS}

Com as mudanças de paradigma na Administração Pública brasileira, demandando maior transparência e profissionalização, as Ouvidorias vêm ganhando destaque. Isso porque a Sociedade cada vez mais clama por um serviço público de qualidade, com respeito aos direitos do cidadão.

Com este breve relato de experiência, buscou-se demonstrar que, nas organizações contemporâneas, ninguém está imune ao assédio moral, e enfrentar o problema requer informação e o compartilhamento de experiências. O reconhecimento do problema e o suporte institucional contribuem para o enfrentamento da violência, e a existência de uma Ouvidoria consolidada, proativa e com credibilidade perante a comunidade universitária faz parte desse suporte.

\section{REFERÊNCIAS}

ANDIFES. MEC admite corte no orçamento 2017, Brasília, 2016. Disponível em: <http://www.andifes.org.br/mec-admite-corte-no-orcamento-2017/>. Acesso em: 08 abr. 2017.

BORGES, T. S.; ALENCAR, G. Metodologias ativas na promoção da formação crítica do estudante: o uso das metodologias ativas como recurso didático na formação crítica do estudante do ensino superior. Cairu em Revista, ano 3, n. 4, p. 119-143, jul./ago. 2014. Disponível em: <http://www.cairu.br/revista/arquivos/artigos/2014_2/08\%20METODOLOGIAS\%20ATIVAS\%20NA\%20PROMOCAO\%20DA\%20FORMACAO\%20CRITICA\%20DO\%20ESTUDANTE. pdf>. Acesso em: 13 jun. 2018.

BRASIL. Assédio moral, assédio sexual e discriminação: saiba mais sobre essas distorções de conduta no ambiente de trabalho. Ouvidoria do Ministério Público Federal, Comitê Gestor de Gênero e Raça. Brasília: MPF, 2016.

Constituição da República Federativa do Brasil de 1988. Disponível em: <http://www.planalto.gov.br/ccivil_03/Constituicao/Constituicao.htm> . Acesso em: 16 out. 2017.

Controle Social: orientações aos cidadãos para participação na gestão pública e exercício do controle social. Controladoria-Geral da União. Brasília, 2012. Disponível em: <http://www.cgu.gov.br/Publicacoes/controle-social/ arquivos/controlesocial2012.pdf>. Acesso em: 16 out. 2017.

Decreto $n^{\circ}$ 8.243. Institui a Política Nacional de Participação Social - PNPS e o Sistema Nacional de Participação Social - SNPS, e dá outras providências. Brasília, 2014. Disponível em: <http://www.planalto.gov.br/ ccivil 03/_Ato2011-2014/2014/Decreto/D8243.htm>. Acesso em: 16 out. 2017.

Lei $n^{\circ}$ 11.153. Dispõe sobre a instituição da Fundação Universidade Federal da Grande Dourados - UFGD, por desmembramento da Fundação Universidade Federal de Mato Grosso do Sul - UFMS, e dá outras providências. Brasília, 2005. Disponível em: <http://www.planalto.gov.br/ccivil_03/_ato2004-2006/2005/lei//11153.htm>. Acesso em: 13 jun. 2018.

Lei $n^{\circ}$ 13.460. Dispõe sobre participação, proteção e defesa dos direitos do usuário dos serviços públicos da Administração Pública. Brasília, 2017. Disponível em: <http://www.planalto.gov.br/ccivil_03/_ato2015-2018/2017/lei/ L13460.htm>. Acesso em: 16 out. 2017.

CNJ. CNJ Serviço: O que é assédio moral e o que fazer? 28 nov. 2016. Disponível em: <http://www.cnj.jus.br/noticias/cnj/84036-cnj-servico-o-que-e-assedio-moral-e-o-que-fazer>. Acesso em: 11 jun. 2018.

CYRILLO, Rose Meire. Ouvidorias: um aporte necessário. Revista do Ministério Público do Distrito Federal e Territórios, v. 9, Brasília, 2015. Disponível em: <http://www.mpdft.mp.br/revistas/index.php/revistas/article/view/190>. Acesso em: 20 dez. 2016. 
GUIMARÃES, C. A.; CANÇADO, V. L.; LIMA, R. J. C. Assédio moral no trabalho e suas consequências: estudo de caso em instituição federal de ensino superior. R. Adm., São Paulo, v. 51, n. 2, p. 151-164, abr./maio/jun. 2016.

HELOANI, R. Violência Invisível. RAE executivo, v. 2, n. 3, ago./out. 2003.

HIRIGOYEN, M. F. A violência perversa do cotidiano. Tradução de Maria Helen Huhner. Rio de Janeiro: Bertrand Brasil, 2001.

Mal-estar no Trabalho: redefinindo o assédio moral. Tradução de Rejane Janowitzer. 3. ed. Rio de Janeiro: Bertrand Brasil, 2006.

MUNIZ, J. A.; MACHADO, F. O.; VIEIRA, D. T. Assédio Moral na Universidade: um estudo de caso em Pernambuco. VIII Convibra Administração - Congresso Virtual Brasileiro de Administração, 2011. Disponível em: <http://www. convibra.com.br/upload/paper/adm/adm_3397.pdf>. Acesso em: 11 jun. 2018.

NASCIMENTO, D. A; ARAÚJO, F. W. C. Assédio moral entre docentes da Universidade Federal do Piauí: sua promoção e seus males na pátria sertaneja. ANDES-SN, ag. 2014. Disponível em: <http://portal.andes.org.br/imprensa/ publicacoes/imp-pub-552752935.pdf>. Acesso em: 12 jun. 2018.

ROMÃO, J. E. E. A Ouvidoria no serviço público brasileiro. In: PAULINO, Fernando Oliveira; SILVA, Luiz Martins da. Comunicação pública em debate. Brasília: Editora da UnB, 2013.

PERSEGUINO, S. A. Processos dialógicos em Ouvidorias universitárias: a experiência da UFSCar. In: Podesta Junior, A.; Pfaffenseller, A. C. A.; Oliveira, A. S. (Org.). Ouvidoria no Brasil e seus desafios: olhares de norte a sul. Florianópolis: Tribo da llha, 2017.

SANTA CATARINA. Secretaria de Estado da Administração. Diretoria de Saúde do Servidor. Assédio moral no serviço público: manual de diretrizes e procedimentos/Secretaria de Estado da Administração. - Florianópolis: Secretaria de Estado da Administração, 2010.

SOBOLL, L. A. P. Intervenções no espaço possível de ação: princípios e estratégias básicas no combate ao assédio moral e organizacional. In: SOBOLL, L. A. P. (Org.). Intervenções em assédio moral e organizacional. São Paulo: LTr 2017.

UFGD. Plano de Desenvolvimento Institucional-PDI-2013-2017. Universidade Federal da Grande Dourados. Dourados: UFGD, 2013. Disponível em: <http://files.ufgd.edu.br/arquivos/arquivos/78/PROAP/PDI\%20APROVADO\%20 PELO\%20COUNI\%20-\%20RES.\%20196-13.pdf>. Acesso em: 13 jun. 2018.

VIEIRA, V. Governo corta $47 \%$ dos investimentos previstos para as federais. O Estado de S. Paulo, São Paulo, 20 jun. 2015. Disponível em: <https://educacao.estadao.com.br/noticias/geral,governo-corta-47-dos-investimentos-previstos-para-universidades-federais,1710033>. Acesso em: 08 abr. 2017.

VIEIRA, V. Universidades federais devem ter corte de até $45 \%$ nos investimentos. O Estado de S. Paulo, São Paulo, 11 ago. 2016. Disponível em: http://educacao.estadao.com.br/noticias/geral,federais-devem-ter-corte-de-ate45-nos-investimentos, 10000068526 >. Acesso em: 08 abr. 2017. 